\title{
A prospective study of atopic dermatitis managed without topical corticosteroids for a 6-month period
}

This article was published in the following Dove Press journal:

Clinical, Cosmetic and Investigational Dermatology

4 July 2016

Number of times this article has been viewed

\section{Mototsugu Fukaya' \\ Kenji Sato ${ }^{2}$ \\ Takahiro Yamada ${ }^{2}$ \\ Mitsuko Sato ${ }^{3}$ \\ Shigeki Fujisawa ${ }^{4}$ \\ Satoko Minaguchi ${ }^{5}$ \\ Hajime Kimata ${ }^{6}$ \\ Haruhiko Dozono ${ }^{7}$ \\ 'Tsurumai Kouen Clinic, Nagoya, ${ }^{2}$ Department of Dermatology, Hannan Chuo Hospital, ${ }^{3}$ Sato Pediatric Clinic, Osaka, ${ }^{4}$ Fujisawa Dermatology Clinic, Tokyo, ${ }^{5}$ Ageofutatsunomiya Clinic, \\ Saitama, ${ }^{6}$ Kimata Hajime Clinic, Osaka, ${ }^{7}$ Dozono Medical House, Kagoshima, Japan}

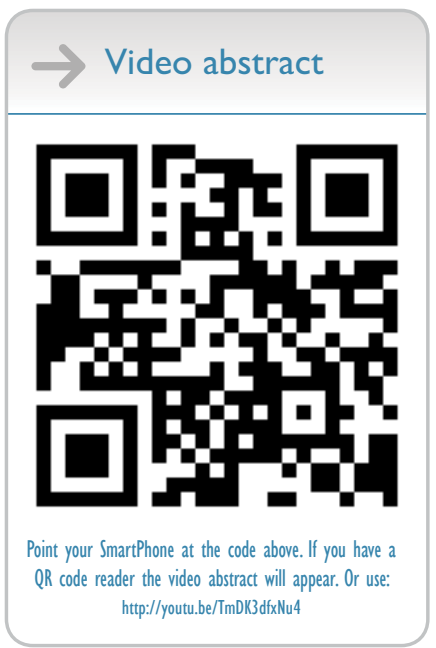

Correspondence: Mototsugu Fukaya Tsurumai Kouen Clinic, 5-20-6 Chiyoda Nakaku, Nagoya 460-00I2, Japan

Tel +8I 522640212

Email moto@earth.ocn.ne.jp
Abstract: Topical corticosteroids (TCS) are regarded as the mainstay treatment for atopic dermatitis (AD). As AD has a tendency to heal naturally, the long-term efficacy of TCS in AD management should be compared with the outcomes seen in patients with AD not using TCS. However, there are few long-term studies that consider patients with AD not using TCS. We designed a prospective multicenter cohort study to assess the clinical outcomes in patients with AD who did not use TCS for 6 months and then compared our results with an earlier study by Furue et al which considered AD patients using TCS over 6 months. Our patients' clinical improvement was comparable with the patients described in Furue's research. In light of this, it is reasonable for physicians to manage AD patients who decline TCS, as the expected long-term prognosis is similar whether they use TCS or not.

Keywords: atopic dermatitis, topical corticosteroids, topical steroid addiction

\section{Introduction}

Atopic dermatitis (AD) has a tendency to self-heal. In a retrospective study of 597 children diagnosed with $\mathrm{AD}$ in the first year of life, Chung et al ${ }^{1}$ found that complete remission was achieved in an average of 29.6 months. This tendency for natural resolution complicates the long-term evaluation of $\mathrm{AD}$ treatments. Iyengar et $\mathrm{al}^{2}$ conducted a double-blind study on omalizumab efficacy in children, with the placebo group avoiding the use of topical corticosteroids (TCS) for 6 months. These placebo patients significantly improved after 6 months, although all children enrolled in the study had severe $\mathrm{AD}$ symptoms failing to respond to standard therapy at the beginning of the trial. ${ }^{2}$

In the short term (several days to weeks in most of the cases), it is recognized that TCS improve the cutaneous symptoms of AD..$^{3-5}$ Recently, a protocol of proactive twice weekly TCS application has been reported to prevent AD flares ${ }^{6-8}$ and decrease the financial burden of the patients. ${ }^{9}$ However, this proactive protocol excluded patients with poorly controlled $\mathrm{AD}$ and studied only patients who succeeded in controlling $\mathrm{AD}$ by TCS use for several weeks following TCS use. Furue et a $1^{10}$ studied the outcomes of AD in patients 6 months after using traditional TCS treatment and found that the rate of "uncontrolled" patients was 7\% in the infant group, $10 \%$ in the children group, and $19 \%$ in the adolescent and adult groups.

As AD has a natural tendency to self-heal, and there are patients who do not improve with TCS use in the long term, the authors decided to conduct a study to determine the clinical severity of AD in patients after 6 months of not using TCS. We believe that our study on the natural course of $\mathrm{AD}$ is highly relevant at a time when 
TCS side effects are being discussed ${ }^{11}$ and new therapies for $\mathrm{AD}$ are being researched. ${ }^{2}$

\section{Materials and methods}

Our prospective multicenter cohort study was registered with the University Hospital Medical Information Network (UMIN000015781) and ethical approval was granted by the Okuma Hospital Ethical Committee, Nagoya, Japan (2014 11 27-1). Patients who met the criteria outlined in the guidelines for the management of $\mathrm{AD}^{12}$ were eligible for this study, and the eligible patients were enrolled between January 2015 and June 2015. Written informed consent was obtained from all patients. The patients were instructed not to use TCS (or specific therapies including calcineurin inhibitors) for 6 months. Conventional conservative treatments such as oral antihistamines and emollients were permitted. Patients were free to drop out of the study and resume TCS at any time if desired.

Our main aim was to compare our patients not using TCS with those in Furue's study who used TCS. In order to aid comparison, we used the same age categories and the severity classification described in Furue's paper. Therefore, "infants" were patients aged 0-1 years, "children" 2-12 years, and "adolescents and adults" $\geq 13$ years of age. Global clinical severity was graded using the classifications "very severe", "severe", "moderate", and "mild". Definitions for these classifications are as follows: very severe - inflamed skin lesions covering $30 \%$ or more of the body surface; severe - inflamed skin lesions covering between $10 \%$ and $30 \%$ of the body surface; moderate - inflamed skin covering $<10 \%$ of the body surface; and mild - dry skin, scaling, and faint erythema. We added the category "remission" for patients with clear skin.

The following data were collected from each patient at the first interview: age, sex, the total period of TCS application from birth till study enrolment (in months), the length of last period during which the patient did not apply TCS (months), the amount of TCS used during the previous 6 months (grams), and the frequency of use of emollients/bar soap/liquid soap (recorded as "nonuse" - 0, "sometimes" -1 , and "everyday" -2 ). Physicians examined the patients at the beginning of the study and again at 6 months for the presence of prurigo (considered a sign of intractability) and adverse effects of TCS (namely telangiectasia on the cheeks and skin atrophy to either cubital or popliteal fossae). The incidence of herpes simplex and/or Kaposi's varicelliform eruption, molluscum contagiosum, and bacterial infection during the study period was recorded at the 6-month review.

\section{Results}

Approximately 357 patients were enrolled and 300 completed the study. There were 118 infants (mean age: $10 \pm 5$ months; 66 males and 52 females), 80 children (mean age: $4 \pm 2$ years; 51 males and 29 females), and 102 adolescents and adults

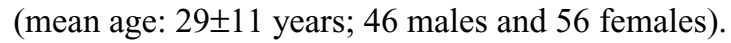

Figure 1 summarizes the pre- and post-treatment severity in the three age-groups. The patients in the yellow background section were deemed to have "uncontrolled" AD, the remainder were considered to have "controlled" $\mathrm{AD}$, with Furue's definition of controlled and uncontrolled AD being used. The patients who showed "non-improvement" in both the studies are enclosed in the red outline. In our study, 12\% (14 of 118 ) of the infants, $9 \%$ (seven of 80 ) of the children, and $30 \%$ (31 of 102) of the adolescent and adults remained in a "very severe" state or "severe" state or experienced exacerbation ("uncontrolled" group).

We attempted to contact the 57 patients who did not complete our study to record their reasons for dropping out and evaluate their present disease severity. Fourteen patients reported that they discontinued for personal reasons and stated that they had improved clinically, seven stated that they had worsened and did not want to attend the follow-up appointment, two had resumed TCS use, three used inhaled steroids for asthma, and 31 could not be contacted. Table 1 documents the severity of AD symptoms in these patients who dropped out. Their disease severity at the commencement of the study was not significantly different from those who did complete the study.

Features on history were compared between patients with "controlled" and "uncontrolled" AD; the results are shown in Table 2. The average total period of TCS application was significantly longer in the "uncontrolled" group than that in the "controlled" group (128.3 months vs 46.7 months). Differences in the other factors studied were not statistically significant - that is, the length of last period during which the patient did not apply TCS, the amount of TCS used during the last 6 months, and the frequency of use of emollients/ bar soap/ liquid soap.

Features on the examination were compared in "controlled" and "uncontrolled" AD patients, and the results are shown in Table 3. Patients with telangiectasia in the cheeks, skin atrophy in the cubital fossa, and skin atrophy in the popliteal fossa were significantly more likely to have "uncontrolled" AD than those without these clinical features. Presence of prurigo did not increase the patient's risk of having "uncontrolled" eczema. 


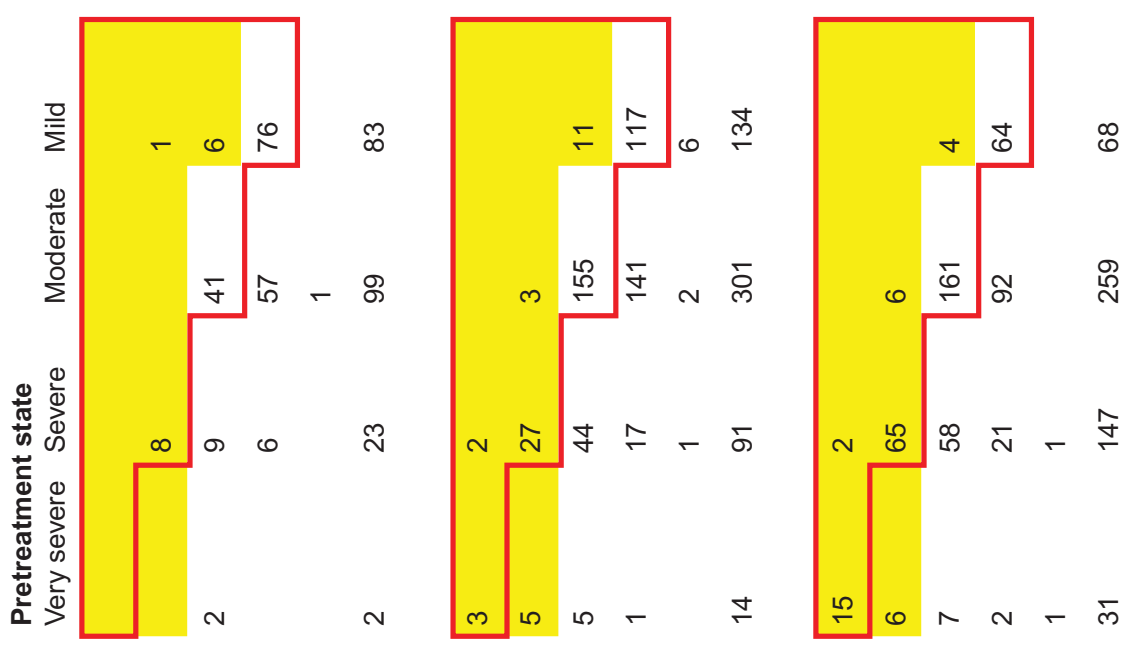

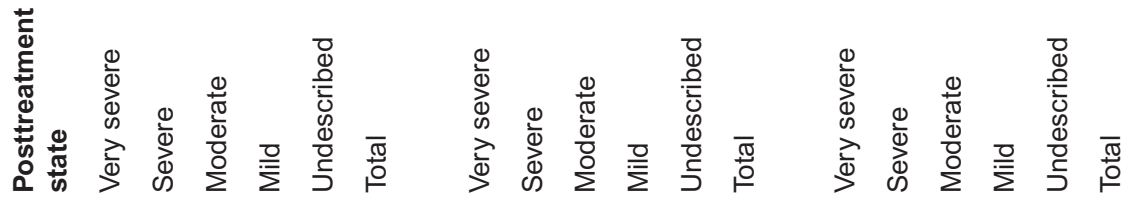
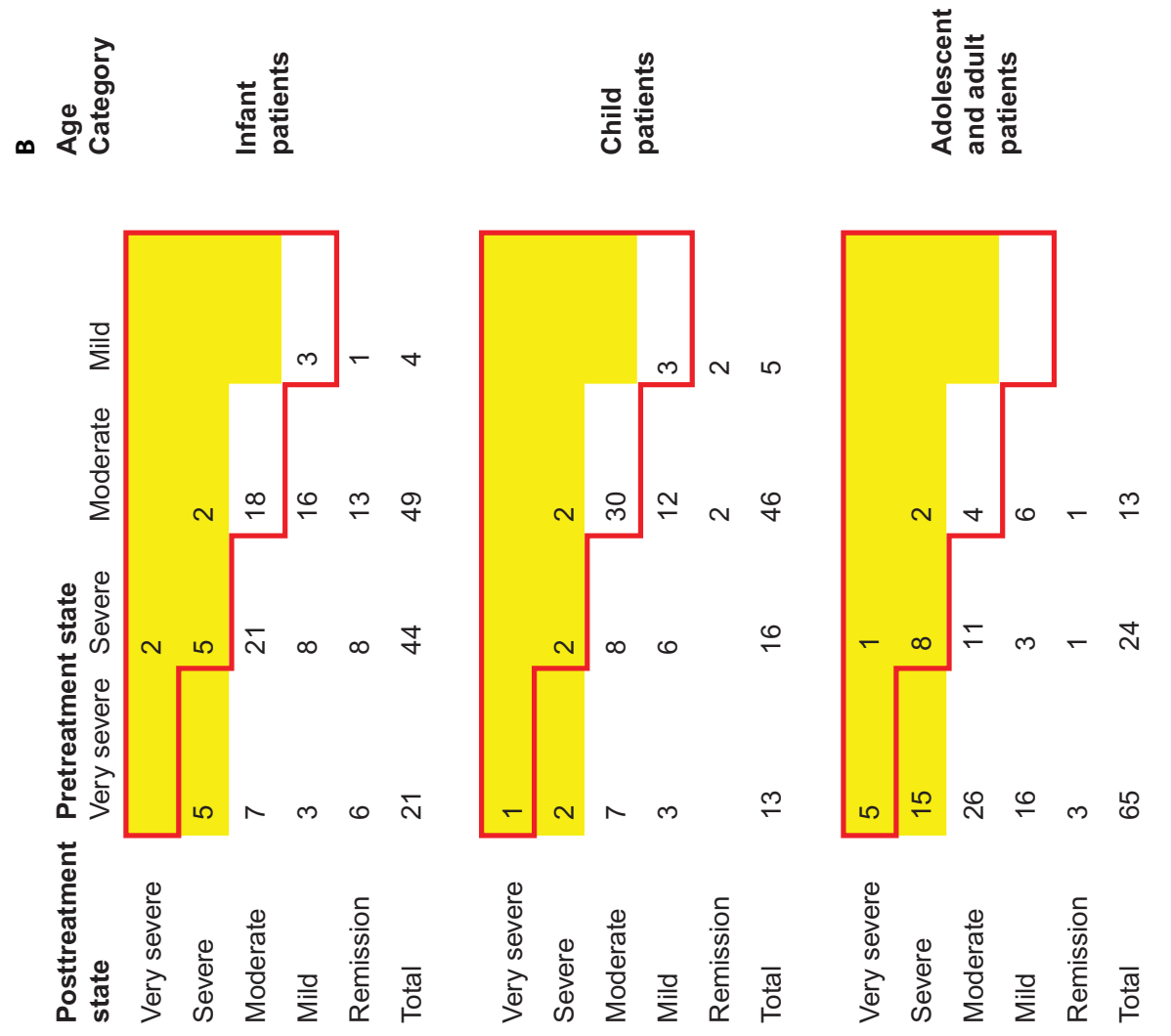

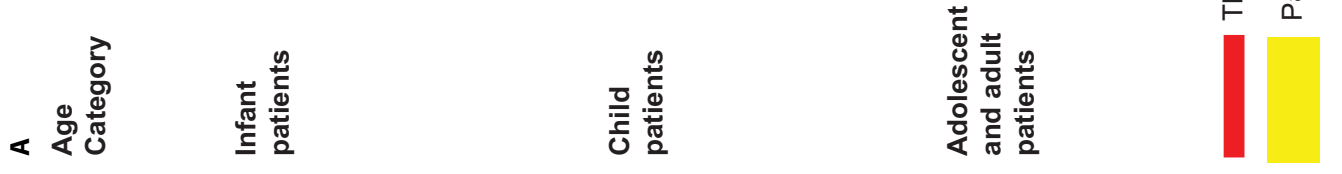

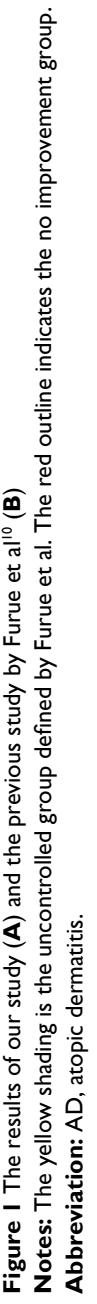


Table I The clinical severity of atopic dermatitis seen at the beginning of the study and reported at 6 months in the group of patients who dropped out of the study

\begin{tabular}{|c|c|c|c|c|c|c|}
\hline \multirow[t]{2}{*}{ Age category } & \multirow{2}{*}{$\begin{array}{l}\text { Posttreatment } \\
\text { state }\end{array}$} & \multicolumn{5}{|c|}{ Pretreatment state } \\
\hline & & Very severe & Severe & Moderate & Mild & Unknown \\
\hline \multicolumn{7}{|l|}{ Infant patients } \\
\hline & Very severe & & & & & \\
\hline & Severe & & & & & \\
\hline & Moderate & 2 & & & & \\
\hline & Mild & & & & & \\
\hline & Remission & & & & & \\
\hline & Unknown & 2 & 5 & 5 & 1 & 2 \\
\hline \multicolumn{7}{|l|}{ Child patients } \\
\hline & Very severe & & & & & \\
\hline & Severe & & & & & \\
\hline & Moderate & 1 & & & & \\
\hline & Mild & & & & & \\
\hline & Remission & & 3 & & & \\
\hline & Unknown & 3 & I & 3 & 2 & \\
\hline \multicolumn{7}{|c|}{ Adolescent and adult patients } \\
\hline & Very severe & 1 & & & & \\
\hline & Severe & 5 & 2 & & & \\
\hline & Moderate & 5 & & & & \\
\hline & Mild & & & & & \\
\hline & Remission & 1 & I & & & \\
\hline & unknown & 2 & 2 & 2 & & 6 \\
\hline
\end{tabular}

Examination findings were compared with the history of TCS application (Table 4). Patients with prurigo were statistically more likely to have had a greater total period of TCS use. Patients with skin atrophy in the cubital fossae and those with skin atrophy in the popliteal fossae were also significantly more likely to have used TCS for a longer period than those patients without these clinical features. Patients with prurigo were significantly more likely to have used a greater quantity of TCS in the past 6 months than those without prurigo.

Table 5 provides the rates of herpes simplex and/or Kaposi's varicelliform eruption, molluscum contagiosum, and bacterial infection during the period. The incidence of these infections was higher than that has previously been reported in patients using TCS. Infection rates were especially high in the "uncontrolled" infants and children.

\section{Discussion}

We compared our results with Furue's study on patients with AD treated with TCS for 6 months. ${ }^{10}$ In the patients of Furue's study, treated with conventional TCS therapy, the following proportions were found to be "uncontrolled": 7\% (15 out of 206 ) of the infants, $10 \%$ (51 out of 531) of the children, and $19 \%$ (98 of 503) of the adolescent and adult patients (Figure 1).

Our group had a greater proportion of "uncontrolled" patients, and this was statistically significant in the adolescent and adult groups. The following were found to be "uncontrolled": $12 \%$ (14 of 118) of the infants, 9\% (seven of 80 ) of the children, and $30 \%$ (31 of 102) of the adolescent and adults. When we compared the proportions of "very severe", "severe", "moderate", and "mild" cases in both the study populations, we found our adolescent and adult patients were significantly more likely to have "very severe" AD than Furue's population. Approximately 63.7\% (65 of 102) were "very severe" in our population versus $6 \%$ (31 of 505) in Furue's. The proportions of "severe" adolescent and adult patients were not significantly different between the two study populations: $23.5 \%$ (24 of 104 ) in our population versus $29 \%$ (147 of 505) in Furue's. Therefore, while our adolescent and adult patients were more likely to have "uncontrolled" AD than Furue's, our population included a much higher proportion of "very severe" cases.

Because of the differences in disease severity between the two study populations, we separated all the patients in their clinical severity category before comparing the outcomes at 6 months. In the "very severe" group, a significantly greater improvement was seen in the patients not using TCS versus the "very severe" patients who did use TCS.

In our study, the following proportions of patients did not improve over the 6 months: $25 \%$ (30 of 118) of the infants, $48 \%$ (38 of 80 ) of the children, and 20\% (20 of 102) of the adolescent and adult patients, whereas in Furue's study, 
Table 2 The difference between the controlled and uncontrolled groups in their use of TCS/emollients/soaps before commencing the study

\begin{tabular}{|c|c|c|}
\hline Information about TCS use & Controlled & Uncontrolled \\
\hline \multicolumn{3}{|l|}{$\begin{array}{l}\text { Total period of TCS } \\
\text { application (months) }\end{array}$} \\
\hline Average & 46.7 & 128.3 \\
\hline Standard variance & 96.4 & 152.9 \\
\hline$P$-value (Student's $t$-test) & $<0.00 I^{*}$ & \\
\hline \multicolumn{3}{|l|}{ The last continuous } \\
\hline \multicolumn{3}{|c|}{ TCS-unapplied period (months) } \\
\hline Average & 19.4 & 23.8 \\
\hline Standard variance & 36.0 & 36.0 \\
\hline$P$-value (Student's $t$-test) & 0.43 & \\
\hline \multicolumn{3}{|l|}{$\begin{array}{l}\text { The amount of applied TCS } \\
\text { for the last } 6 \text { months (g) }\end{array}$} \\
\hline Average & 15.0 & 20.0 \\
\hline Standard variance & 54.7 & 67.4 \\
\hline$P$-value (Student's $t$-test) & 0.56 & \\
\hline \multicolumn{3}{|l|}{$\begin{array}{l}\text { The frequency of the use } \\
\text { of emollients (three grade } \\
\text { evaluation from } 0 \text { to } 2 \text { ) }\end{array}$} \\
\hline Average & 0.94 & 0.81 \\
\hline Standard variance & 0.72 & 0.74 \\
\hline$P$-value (Student's $t$-test) & 0.23 & \\
\hline \multicolumn{3}{|c|}{$\begin{array}{l}\text { The frequency of the use of bar } \\
\text { soap } \\
\text { (three grade evaluation from } 0 \\
\text { to } 2 \text { ) }\end{array}$} \\
\hline Average & 0.77 & 0.83 \\
\hline Standard variance & 0.66 & 0.68 \\
\hline$P$-value (Student's $t$-test) & 0.54 & \\
\hline \multicolumn{3}{|l|}{$\begin{array}{l}\text { The frequency of the use of } \\
\text { liquid soap (three grade } \\
\text { evaluation from } 0 \text { to } 2 \text { ) }\end{array}$} \\
\hline Average & 0.31 & 0.35 \\
\hline Standard variance & 0.61 & 0.62 \\
\hline$P$-value (Student's $t$-test) & 0.67 & \\
\hline
\end{tabular}

Note: *Statistically significant.

Abbreviation: TCS, topical corticosteroids.

these figures for nonimprovement were $64 \%$ (132 of 206), $60 \%$ (318 of 531), and 63\% (317 of 503), respectively. This shows that the rate of "nonimprovement" was actually higher in patients using TCS than those not, in all age categories. As research was conducted at a different time and place when compared to Furue's study, caution is needed while comparing the data. However, we have shown that a significant percentage of $\mathrm{AD}$ patients improved in 6 months without using TCS. The proportion of patients who improved was: $75 \%$ (88 of 118) of the infants, $52 \%$ (42 of 80 ) of the children, and $80 \%$ ( 82 of 102) of the adolescent and adults. It is worth noting that $24 \%$ (28 of 118) of the infants had clear skin (ie, were in remission) at the end of the follow-up.

The difference in the average period of TCS use in the "controlled" and "uncontrolled" patients could be interpreted
Table 3 Comparing the presence and absence of clinical features (prurigo, teleangiectasia, and skin atrophy) seen at the commencement of study in controlled and uncontrolled atopic dermatitis patients

\begin{tabular}{|c|c|c|c|}
\hline \multirow[t]{2}{*}{$\begin{array}{l}\text { Clinical outcome } \\
\text { after six months }\end{array}$} & \multicolumn{3}{|c|}{$\begin{array}{l}\text { Clinical features seen on } \\
\text { examination at commencement } \\
\text { of study }\end{array}$} \\
\hline & Prurigo (+) & Prurigo (-) & Unknown \\
\hline Controlled & 12 & 232 & 4 \\
\hline Uncontrolled & 4 & 47 & 1 \\
\hline \multirow[t]{2}{*}{ Fisher's exact test } & $P=0.4922$ & & \\
\hline & $\begin{array}{l}\text { Teleangiectasia } \\
\text { of the cheeks } \\
(+)\end{array}$ & $\begin{array}{l}\text { Teleangiectasia } \\
\text { of the cheeks } \\
(-)\end{array}$ & Unknown \\
\hline Controlled & 14 & 234 & \\
\hline Uncontrolled & 8 & 44 & \\
\hline \multirow[t]{3}{*}{ Fisher's exact test } & $P=0.0343 *$ & & \\
\hline & $\begin{array}{l}\text { Skin atrophy to } \\
\text { the cubital fossa }\end{array}$ & $\begin{array}{l}\text { Skin atrophy to } \\
\text { the cubital fossa }\end{array}$ & Unknown \\
\hline & $(+)$ & $(-)$ & \\
\hline Controlled & 36 & 212 & \\
\hline Uncontrolled & 18 & 34 & \\
\hline \multirow[t]{2}{*}{ Fisher's exact test } & $P=0.0013^{*}$ & & \\
\hline & $\begin{array}{l}\text { Skin atrophy } \\
\text { to the popliteal } \\
\text { fossa }(+)\end{array}$ & $\begin{array}{l}\text { Skin atrophy } \\
\text { to the popliteal } \\
\text { fossa (-) }\end{array}$ & Unknown \\
\hline Controlled & 11 & 237 & \\
\hline Uncontrolled & 6 & 12 & \\
\hline Fisher's exact test & $P=0.0003^{*}$ & & \\
\hline
\end{tabular}

Note: *Statistically significant.

in two ways. The period of TCS use could correspond with the duration of $\mathrm{AD}$ (as would be expected in patients who are not "steroid phobic"). It would not be surprising for patients with longer histories of $\mathrm{AD}$ to show lower rates of improvement at 6 months than those patients with shorter durations of symptoms. Another explanation is that prolonged use of TCS might result in the difficulty to cure AD. This suggestion may sound absurd to many dermatologists. However, literature exists to support this possibility. Topical steroid addiction $^{11,13-15}$ also known as the red burning skin syndrome ${ }^{15}$ may occur after prolonged use of TCS and has been discussed for many years. The skin produces cortisol, and so prolonged application of TCS can suppress this cortisol production in the same way that systemic steroids suppress the production of cortisol in the adrenal gland. Once the production of cortisol in the skin is impaired, irritants and allergens from the environment cause increased inflammation unless there is a consistent supply of TCS, and so the eczema becomes refractory. Prolonged use of TCS has been shown to cause a patchy defect of cortisol staining in the epidermis. ${ }^{16}$

The finding that telangiectasia on the cheeks and skin atrophy at both the cubital and popliteal fossae are associated 
Table 4 Comparing the examination findings at the start of the study with the reported history of TCS use

\begin{tabular}{|c|c|c|c|c|c|c|c|c|}
\hline \multirow[t]{2}{*}{ Clinical feature } & \multicolumn{2}{|c|}{ Prurigo } & \multicolumn{2}{|c|}{$\begin{array}{l}\text { Teleangiectasia in the } \\
\text { cheeks }\end{array}$} & \multicolumn{2}{|c|}{$\begin{array}{l}\text { Skin atrophy in the } \\
\text { cubital fossa }\end{array}$} & \multicolumn{2}{|c|}{$\begin{array}{l}\text { Skin atrophy in the } \\
\text { popliteal fossa }\end{array}$} \\
\hline & No & Yes & No & Yes & No & Yes & No & Yes \\
\hline \multicolumn{9}{|l|}{ Total period of TCS } \\
\hline \multicolumn{9}{|l|}{ application (months) } \\
\hline Average & 53.7 & 170.2 & 57.4 & 104.5 & 44.6 & 134.9 & 54.4 & 167.5 \\
\hline Standard variance & 107.6 & 137.5 & 110.1 & 132.1 & 99.1 & 137.9 & 104.5 & 174.2 \\
\hline$P$-value (Student's $t$-test) & $<0.001 *$ & & 0.058 & & $<0.00 I^{*}$ & & $<0.00 I^{*}$ & \\
\hline & & & & & & & & \\
\hline which the patient did & & & & & & & & \\
\hline \multicolumn{9}{|l|}{ TCS (months) } \\
\hline Average & 20.5 & 17.5 & 20.8 & 11.5 & 18.7 & 26.6 & 20.4 & 15.7 \\
\hline Standard variance & 38.2 & 21.3 & 38.4 & 11.4 & 34.1 & 48.7 & 38.1 & 15.4 \\
\hline$P$-value (Student's $t$-test) & 0.76 & & 0.26 & & 0.16 & & 0.61 & \\
\hline \multirow{2}{*}{\multicolumn{9}{|c|}{$\begin{array}{l}\text { The amount of TCS used during } \\
\text { the previous } 6 \text { months (g) }\end{array}$}} \\
\hline & & & & & & & & \\
\hline Average & 13.7 & 44.7 & 16.2 & 11.8 & 14.4 & 22.6 & 15.7 & 18.4 \\
\hline Standard variance & 53.5 & 102.0 & 59.0 & 18.9 & 19.1 & 47.7 & 58.2 & 33.8 \\
\hline$P$-value (Student's $t$-test) & $0.04 *$ & & 0.73 & & 0.34 & & 0.85 & \\
\hline
\end{tabular}

Note: *Statistically significant.

Abbreviation: TCS, topical corticosteroids.

Table 5 The incidence of herpes simplex andor Kaposi's varicelliform eruption, molluscum contagiosum, and bacterial infection during the study period

\begin{tabular}{lllll}
\hline $\begin{array}{l}\text { Age } \\
\text { category }\end{array}$ & $\begin{array}{l}\text { Clinical } \\
\text { outcome } \\
\text { after 6 } \\
\text { months }\end{array}$ & $\begin{array}{l}\text { Herpes } \\
\text { simplex } \\
\text { infection } \\
\text { andor } \\
\text { Kaposi's } \\
\text { varicelliform } \\
\text { eruption }\end{array}$ & $\begin{array}{l}\text { Molluscum } \\
\text { contagiosum }\end{array}$ & $\begin{array}{l}\text { Bacterial } \\
\text { infection }\end{array}$ \\
\hline Adolescent & Total & 0.18 & 0.01 & \\
and adults & Controlled & 0.16 & 0.00 & 0.16 \\
Children & Uncontrolled & 0.22 & 0.03 & 0.14 \\
& Total & 0.18 & 0.04 & 0.19 \\
& Controlled & 0.14 & 0.04 & 0.16 \\
Infants & Uncontrolled & 0.50 & 0.00 & 0.83 \\
& Total & 0.14 & 0.02 & 0.31 \\
& Controlled & 0.11 & 0.02 & 0.29 \\
& Uncontrolled & 0.43 & 0.00 & 0.43 \\
\hline
\end{tabular}

with "uncontrolled" AD also suggests that patients with the evidence of adverse effects from TCS tend to become refractory. The finding that patients with prurigo, telangiectasia on the cheeks, and skin atrophy at the cubital or popliteal fossae were significantly more likely to have had a greater total period of TCS use suggests that these clinical findings are associated with the prolonged use or the use of a large amount of TCS.

The high incidence of secondary infection during the 6-month period was of concern, although all our patients were treated promptly and recovered quickly. If $\mathrm{AD}$ patients not using TCS are discouraged from seeking medical attention and they develop an infection, they could be at greater risk of life-threatening sepsis or dehydration. This is worth considering when physicians may be reluctant to treat patients declining TCS. However, the so-called steroid phobic patients ${ }^{17,18}$ is a hot topic in dermatology. Although there are many guidelines on $\mathrm{AD}$ management, there are no guidelines on managing $\mathrm{AD}$ in patients without using TCS..$^{12,19-21}$

Since the long-term prognosis in AD patients using TCS is not superior to those not using TCS, and there is evidence that a significant number of AD patients improve without using TCS, managing patients declining TCS should be an acceptable scenario. Moreover, if these patients have topical steroid addiction in addition to $\mathrm{AD}$, their symptoms will not resolve unless they cease using TCS. If physicians decline to manage these patients and they are left without medical supervision, then they would be at greater risk of an adverse outcome due to secondary infections..$^{22}$ Hence, we believe that physicians treating AD patients should be open to managing them without the use of TCS, if the patient is competent and makes this choice. In this situation, the physician waits and watches until the eczema naturally heals, while managing any complications such as infection.

The authors would like to respond to one reviewer who made the following comment about this article: "I think there is a misunderstanding about the goals of treatment here: it is to help manage the severe itch, broken skin, and disrupted sleep? Even for steroid-phobic patients - and especially for 

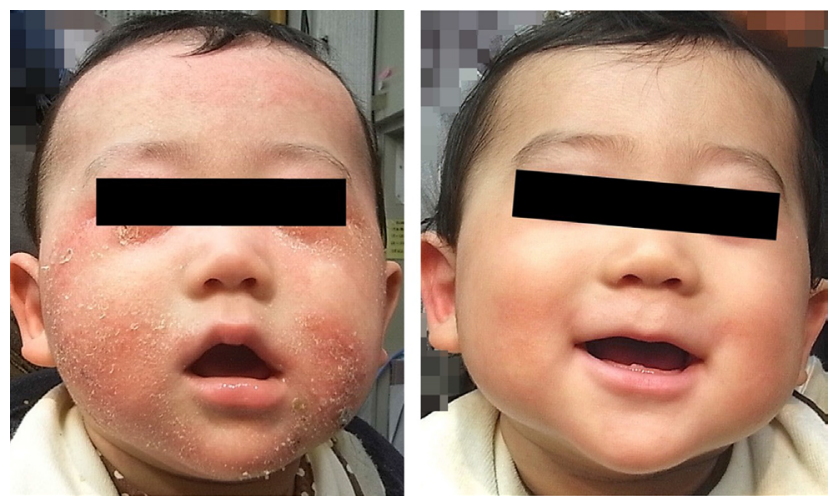

Figure 2 An infant with moderately severe atopic dermatitis (left).

Note: The patient did not use TCS and 4 months later was assessed as being in remission.

Abbreviation: TCS, topical corticosteroids.

severe patients - I deem it unethical to simply watch and wait. Yes, the flare will likely end in time, but why not help them in the short term?" This opinion might be the commonest one among dermatologists at present. If there is no risk of topical steroid addiction as a side effect of prolonged use of TCS, the reviewer is absolutely right. However, is it really "unethical" to watch and wait without using TCS for a patient such as that shown in Figure 2? The parents declined to use TCS on their baby and as a result denied a medical consultation with a particular doctor. It was suggested that their decision amounted to negligence. In our opinion, medical negligence is committed by physicians who deny care in cases such as this.

\section{Conclusion}

In our study over 6 months, a considerable number of patients with AD improved without using TCS. Although the short-term efficacy of TCS is excellent in AD, the long-term efficacy must be cautiously assessed when it is appreciated that this condition has a tendency to self-heal.

\section{Disclosure}

The authors report no conflicts of interest in this work.

\section{References}

1. Chung Y, Kwon JH, Kim J, Han Y, Lee SI, Ahn K. Retrospective analysis of the natural history of atopic dermatitis occurring in the first year of life in Korean children. J Korean Med Sci. 2012;27:723-728.

2. Iyengar SR, Hoyte EG, Loza A, Bonaccorso S, Chiang D, Umetsu DT, Nadeau KC. Immunologic effects of omalizumab in children with severe refractory atopic dermatitis: a randomized, placebo-controlled clinical trial. Int Arch Allergy Immunol. 2013;162:89-93.

3. Sulzberger MB, Witten VH. The effect of topically applied compound F in selected dermatoses. J Invest Dermatol. 1952;19(2):101-102.
4. Scholtz JR. A new corticoid for topical therapy. Fluocinolone acetonide. Calif Med. 1961;95:224-226.

5. Feher PJ, Graham A, Kalz F. Topical application of flurandrenolone in the treatment of atopic dermatitis. Can Med Assoc J. 1963;89:82-83.

6. Van Der Meer JB, Glazenburg EJ, Mulder PG, Eggink HF, Coenraads PJ The management of moderate to severe atopic dermatitis in adults with topical fluticasone propionate. The Netherlands Adult Atopic Dermatitis Study Group. Br J Dermatol. 1999;140(6):1114-1121.

7. Berth-Jones J, Damstra RJ, Golsch S, Livden JK, Van Hooteghem O, Allegra F, Parker CA; Multinational Study Group. Twice weekly fluticasone propionate added to emollient maintenance treatment to reduce risk of relapse in atopic dermatitis: randomised, double blind, parallel group study. BMJ. 2003;326(7403):1367.

8. Peserico A, Städtler G, Sebastian M, Fernandez RS, Vick K, Bieber T. Reduction of relapses of atopic dermatitis with methylprednisolone aceponate cream twice weekly in addition to maintenance treatment with emollient: a multicentre, randomized, double-blind, controlled study. Br J Dermatol. 2008;158:801-807.

9. Healy E, Bentley A, Fidler C, Chambers C. Cost-effectiveness of tacrolimus ointment in adults and children with moderate and severe atopic dermatitis: twice-weekly maintenance treatment vs. standard twice-daily reactive treatment of exacerbations from a third party payer (UK National Health Service) perspective. Br J Dermatol. 2011;164(2): 387-395.

10. Furue M, Terao H, Rikihisa W, Urabe K, Kinukawa N, Nose Y, Koga T. Clinical dose and adverse effects of topical steroids in daily management of atopic dermatitis. Br J Dermatol. 2003;148(1):128-133.

11. Hengge UR, Ruzicka T, Schwartz RA, Cork MJ. Adverse effects of topical glucocorticosteroids. J Am Acad Dermatol. 2006;54(1): $1-15$.

12. Saeki H, Furue M, Furukawa F, Hide M, Ohtsuki M, Katayama I, et al. Guidelines for management of atopic dermatitis. JDermatol.2009;36(10): 563-577.

13. Fukaya M, Sato K, Sato M, Kimata H, Fujisawa S, Dozono H, Yoshizawa J, Minaguchi S. Topical steroid addiction in atopic dermatitis. Drug Healthc Patient Saf. 2014;6:131-138.

14. Hajar T, Leshem YA, Hanifin JM, et al. A systematic review of topical corticosteroid withdrawal ("steroid addiction") in patients with atopic dermatitis and other dermatoses. J Am Acad Dermatol. 2015;72(3): 541-549.

15. Rapaport MJ, Lebwohl M. Corticosteroid addiction and withdrawal in the atopic: the red burning skin syndrome. Clin Dermatol. 2003;21(3): 201-214.

16. Fukaya M. Histological and immunohistological findings using anticortisol antibody in atopic dermatitis with topical steroid addiction. Dermatol Ther (Heidelb). 2016;6(1):39-46.

17. Furue M, Chiba T, Takeuchi S. Current status of atopic dermatitis in Japan. Asia Pac Allergy. 2011;1(2):64-72.

18. Lee JY, HerY, Kim CW, Kim SS. Topical corticosteroid phobia among parents of children with atopic eczema in Korea. Ann Dermatol. 2015;27(5): 499-506.

19. Eichenfield LF, Tom WL, Berger TG, et al. Guidelines of care for the management of atopic dermatitis: section 2. Management and treatment of atopic dermatitis with topical therapies. JAm Acad Dermatol. 2014;71(1): $116-132$.

20. Katayama I, Kohno Y, Akiyama K, et al. Japanese Guideline for Atopic Dermatitis 2014. Allergol Int. 2014; 63(3):377-398.

21. Kim JE, Kim HJ, Lew BL, et al. Consensus Guidelines for the Treatment of Atopic Dermatitis in Korea (Part I): General Management and Topical Treatment. Ann Dermatol. 2015;27(5):563-577.

22. Smith SD, StephensAM, Werren JC, Fischer GO. Treatment failure in atopic dermatitis as a result of parental health belief. Med JAust. 2013;199(7): $467-469$. 


\section{Publish your work in this journal}

Clinical, Cosmetic and Investigational Dermatology is an international, peer-reviewed, open access, online journal that focuses on the latest clinical and experimental research in all aspects of skin disease and cosmetic interventions. This journal is included on PubMed. The manuscript management system is completely online

Submit your manuscript here: https://www.dovepress.com/clinical-cosmetic-and-investigational-dermatology-journal

and includes a very quick and fair peer-review system, which is all easy to use. Visit http://www.dovepress.com/testimonials.php to read real quotes from published authors 